\title{
A Social Engagement: How Ecopsychology Can Benefit From Dialogue With the Social Sciences
}

\section{Matthew Adams}

School of Applied Social Science, University of Brighton, Brighton, UK.

\section{Abstract}

The argument put forward in this paper is that ecopsychology would benefit from engaging in more dialogue with developments in the social sciences. The benefits are predominantly in terms of enriching ecopsychological understandings of how we might encourage connectedness to nature and environmental advocacy and discourage environmentally distructive behaviors. More particularly, recent work in the social sciences asserts that existing models of behavior are unlikely to lead to changes on the scale necessary to create something akin to genuinely sustainable societies. The article draws on theory and research emphasizing the irreducible relationship between the psychological and the social, as a basis for better understanding the apparent obstinacy of environmentally destructive behavior and for interventions that offer the hope of change.

... any attempt to develop a sustainable society has to understand how the relationships between individuals and their social contexts can be changed. (Uzzell \&t Räthzel, 2009, p. 340)

\section{T}

here have been numerous recent attempts to comprehensively survey dominant themes in ecopsychology and related psychologies of the environment (e.g., Paidas, 2011; Thompson, 2009). These reviews provide an invaluable guide to how human and nonhuman nature relationships, including those at the core of ecological degradation, are understood across a broad disciplinary base. However, this article looks beyond psychology to developments elsewhere in the social sciences. It is argued that we find there a rapidly developing account of topics relevant to ecopsychologists, not least novel conceptualizations of the role of human behavior and experience in environmental problems and solutions. The paper offers brief outlines of various attempts to theorize social practices as a basic unit of analysis, rather than individual behavior, and related implications for bringing about effective personal and social change in the direction of sustainability. In conclusion, it is argued that ecopsychology can benefit by engaging with contemporary conceptualizations of the way the social is mutually implicated in individual behavior and experience.

\section{The Psychological and the Social}

Ecopsychology is concerned with the psychic and emotional aspects of human-nonhuman nature connectedness and ecological degradation, and to some extent the social dimensions, particularly when this relationship is problematized in terms of environmental crisis. In fact, foundational work in ecopsychology has conceptualized the interplay of aspects of sociocultural infrastructure and norms with the personal and subjective, emphasizing the cultural pathologies underpinning environmentally destructive behaviors (Kidner, 2001; Roszak, 1992). By contrast, it is argued that sociology and social theory has only belatedly contributed to an attempt to understand the role of human behavior in both reproducing and potentially overcoming environmental crisis (Kasper, 2009; Shove, 2010). However, a substantial level of theory and research is now emerging in these fields that significantly overlaps with ecopsychological concerns (e.g., Beck, 2010; Davis, 2010; Jackson, 2008; Kasper, 2009; Lertzman, 2012; Shove, 2010). This work arguably extends our understanding of the social dimension of human-nonhuman nature connectedness and ecological degradation. Perhaps more importantly, there is renewed interest in the psychosocial, where the interplay of the social and psychological or "the 
interconnectedness of society and the psyche" (Cavalletto, 2007, p. 4) is granted primary ontological status, rather than one being a poor cousin of the other in some form. Although a comprehensive summary is beyond the scope of this paper, it is possible to identify some developments in the literature that amount to a critical consensus of sorts. This consensus may provide the basis for further dialogue between ecopsychology, sociology, psychosocial theory, and social theory.

A key claim in this developing literature is that social context has been undertheorized and researched in psychological work on environmental problems and solutions, resulting in individualistic understanding of human practices and misguided policy interventions assuming people behave as rational agents (e.g., Szerszynski \& Urry, 2010, p. 3). This is something of a caricature of conceptualizations of the social world in psychologies of the environment. The psychological mainstream, as far as it is distinguishable, also now acknowledges that psychological research needs to provide a much more nuanced understanding of the multiple and interdependent behavioral decisions involved in patterns of consumption and environmental destruction, even if government policy is slow to catch up (Webb, 2012). However, common practice subsequent to this tends to acknowledge social/ cultural factors as "variables" in mapping "drivers" of human behavior, with the individual as the prime unit of analysis (Steg and Vlek, 2009; Swim et al., 2011).

The failure to fully engage with the social here perhaps reflects a broader historical "hesitancy," particularly in American psychology (Fiske, 2012). As to the reasons why, it may be that established psychology has simply reflected the individualism inherent in the dominant social paradigm of Western modernity (Kidner, 2001). Beyond this possibility, we can only speculate, along with Fiske, that to psychologists the social can seem too "unwieldy, too macro; others because it seems too correlational or descriptive, not enough experimental control” (2012, p. 6).

Uzzell and Räthzel admonish psychology, and even social psychology, for forwarding "individualistic and reductionist models of behavior which have rarely positioned behavior within its larger social, economic and political context" (2009, p. 341). Surprisingly, their argument appears at the heart of the Journal of Environmental Psychology, long considered the voice of the more cautious older sibling to ecopsychology (e.g., Reser, 1995). In developing their argument, Uzzell and Räthzel advocate a "transformative environmental psychology” and related education program (see also Räthzel \& Uzzell, 2009). Transformative environmental psychology is evoked as a way of progressing a "strong" sustainable agenda via a shift in emphasis. The shift is away from an attempt to map, predict, and shape even the widest range or most careful separation of individual attitudes, behaviors, and choices toward an understanding of the individual in context, addressing "specific cultural contexts as well as [the] broader consumerist societal context” (p. 432).

\section{Conceptualizing Psychosocial Practices}

Recent social theory and environmental psychology suggest that what is required instead is a very particular understanding of where the social meets the psychic, the basic unit of psychosocial analysis, as practice (Hand et al., 2005; Shove, 2003, 2010; Webb, 2012). To be understood as the basic unit of analysis, practices have been framed by social and cultural theorists as conveyors of significant symbolic and cultural meanings. These meanings do not originate with individuals but are embodred in individual performances (Law and Urry, 2004). Reckivitz (cited in Warde, 2004, p. 134) defines practices in that sense as follows:

Thus, she or he is not only a carrier of patterns of bodily behaviour, but also of certain routinized ways of understanding, knowing how and desiring. These conventionalized "mental" activities of understanding, knowing how and desiring are necessary elements and qualities of a practice in which the single individual participates, not qualities of the individual.

Ordinary and habitual practices are social in that they follow routines devised from convention-taken-for-granted stocks of knowledge that reveal culture-specific learning: people are creatures of social routine and habit and of fashion and fad (Goffman, 1967): "These patterns of routine and fashion stem from how people are locked into and reproduce many different kinds of social institutions, both old and new" (Szerszynski \& Urry, 2010, p. 3). Institutions cited in this context include families, households, class, gender, work, school, ethnicity, age, nation, scientific communities, NGOs, and broader cultural worldviews and technological systems "that shape people's sense of what is permissible, desirable and possible" (Szerszynski \&t Urry, 2010, p. 3).

Practices are also conceptualized as social in that they are fundamentally relational; that is, they are realized in relation to, and in conjunction with, real and imagined others. An emphasis on sociality is clear in Uzzell and Räthzel's advocacy of a "transactionalist" perspective. It explicitly recognizes that individual and external worlds are permeable, linked in complex and mutual ways, which can only be treated as interrelated phenomenon. Reciprocity and permeability becomes the unit of analysis, where the individual, the social group, or the setting can only be defined with reference to the others. The environment embodies the psychologies and the social 


\section{ADAMS}

relations of those who live in it. It confers meaning, promotes identity, and locates the person socially, culturally and economically.

The primacy of social practices shifts attention away from a focus on the individual and, say, his or her connectedness to nature, and toward the relationship between everyday practices and the opportunities, validations, norms, and so on they create around "connecting to nature" as a possible performance, and actual opportunities for affective bodies resonating with nature (Kidner, 2001). Consider how this emphasis frames an activity such as consumption, or more specifically its entrenchment as a way of life in consumerism. Consumerism is understood as a symbolic activity providing embodied meaning in the pursuit of pleasure, however fleeting, problematic, and partial this pleasure might be. And norms of consumption are formulated in the constant relational work of validating (or repudiating) social narratives, practices, and performances associated with consumption.

If we accept it is a set of practices in reciprocal relation via which particular ways of life are constituted, where does it leave the search for solutions to environmental problems? In the most basic terms, if the consumption-oriented social practices that coalesce in a consumer society perform the "vital sociological role" of creating and maintaining a meaningful social world, psychological work focusing on the internal or structural "barriers" to sustainable consumption and a normative critique of consumption misses the point. When applied to environmentally sustainable or destructive behavior, the implications for social scientific understanding are deceptively simple: "the majority of environmentally significant consumption is undertaken not for its own sake but as part of the ordinary accomplishment of everyday life" (Shove, 2010, p. 282; Warde, 2005). There is a therefore a call for "concerted effort to conceptualize the relative fluidity and fixity of what have come to be ordinary, but ultimately untenable, ways of life" (Shove, 2010, p. 283).

An emphasis on individual practices as reciprocally embedded in social and relational contexts now amounts to what I will call an emerging "critical consensus," at least among those of us frustrated with limited economic and individualist models of behavior change (Webb, 2012). This shift reframes how we think about "barriers" to sustainable behaviors, and related understandings of the individual. It moves beyond the discourses of behavior change and in doing so forces a rethink of how central cultural patterns of meaning and supportive social structures are to the validation of practices considered problematic in the context of a "strong" sustainability agenda: "it is important to tackle the cultural as well as the societal structures that support such practices if one wants to achieve behaviour change" (Uzzell and Räthzel, 2009, p. 341).
A parallel concern is surely a consideration of what kinds of cultural and social constellations support and validate alternative practices, either potential or existing (Kingsnorth \& Hine, 2009). Rather than asking questions about individual behavior and attitude, we must ask how we might engender "circumstances which could enable subordinated or shadow understandings to develop substantively, to be acknowledged and to be acted on systematically" (Webb, 2012, p. 122). In this light, purposeful interventions, including those carried out in the name of psychology, will benefit from incorporating psychosocial perspectives, as they gain more prominence in academic research, public debate, and policy making (Cavalletto, 2007)-resourcing communities, projects, and research that make alternative networks of meaning and pleasure viable (e.g., Kasper, 2008; Schneider and Miller, 2011).

The intention here is not to downplay how much of an obstacle to change "our" (as in wealthier inhabitants of consumer societies) embroilment in the obdurate social and cultural norms of consumer capitalism pose, nor is it to suggest that the ongoing adversities that afflict so many across the globe can be magically lifted via an appeal to alternative practices. Clearly this all gets in the way of the formation of alternative networks and practices; social practices do not emerge from a vacuum. That said, alternative practices must, and do, emerge from existing social and psychological realties, however extensive the colonization of affect (Kidner, 2001); and they have transformative potential. A great deal of recent work across the disciplines has attempted to conceptualize alternatives, even if they are often described with necessary ambiguity as "shadows" (Webb, 2012), “cracks” (Holloway, 2010) or "surplus affect” (Lertzman, 2012, p. 99).

It is possible to begin to flesh out the "assemblages of social practices" that could, or already do, constitute successful sustainable lifestyles. For some this is in fact an urgent imperative: "to raise our imaginations to the challenge of the Anthropocene, we must be able to envision alternative configurations of agents, practices and social relations" (Davis, 2010, p. 44). A range of work engages in articulating and advocating alternative practices more fully: Kate Soper's conceptualization of alternative hedonism, an explicit attempt to consider the joined-up pleasures of less consumption and nonconsumption and how such practices might gain broader cultural validation (Soper, 2007; Soper et al., 2009); Tim Jackson's similar emphasis on the "gains" of sustainable lifestyles (2008); Ulrich Beck's optimistic account of a "green modernity" (2010); Paul Kingsnorth and Dougland Hine's call to radically reformulate the "narratives we live by" (2010). More familiar might be Andy Fisher's call to radicalize ecopsychology and his emphasis on "recollective practices" (2002), and the practice and study of alternative communities such as 
transition towns (Chatterton \& Cutler, 2008) and ecovillages (Kasper, 2008, 2009).

Despite their differences, these studies share an attempt to articulate human activity as a space of practices invested with affect, in dynamic relationship with others, implicitly or explicitly embedding practices in social and cultural networks of validation, as vital to an understanding of environmental problems and solutions. The next section will attempt to flesh out how an understanding of social practices has been developed in recent work by Deborah Kasper and will consider how her work may be of relevance to ecopsychology.

\section{Ecological Habitus}

Kasper makes the now-familiar argument that the epistemological underpinnings of much research into the human and nonhuman nature relationship reflect "an enduring modern Western worldview" rooted in dualistic and mechanist understandings of human behavior in which "a person is viewed as a discrete entity set in opposition to an external world" (2009, p. 3). Behavior from this perspective has no reciprocal influence on cause-this level of interrelation introduces too much complexity and uncertainty into the model. But the reciprocal nature of interrelated processes is the norm for the emerging psychosocial models discussed above, and Kasper advances something similar. Social life is not a "series of changes brought about in static states by the reactions of dependent variables to independent variables but...an ongoing process always embedded in interdependent relations" (Kasper, 2009, p. 4; emphasis in the original).

Kasper's discussion then draws on the themes we have identified above in arguing for a "Relational Process Approach." She develops the late social theorist Pierre Bourdieu's concept of habitus/field to explicitly incorporate an ecological approach in the "ecological habitus." According to Bourdieu, field refers to the always existing, obligatory boundaries of experiential context: "a relational configuration endowed with a specific gravity which it imposes on all the objects and agents which enter it" (Bourdieu, cited in Widick, 2003, p. 684). Fields allow and demand certain responses repeatedly over time to the point of habituation; hence "habitus" is the collective term for this array of dispositions. The habitus thus signifies not just how we think about the world but embodied articulations (Bourdieu, 1977, p. 85-87). The habitus is both thoroughly individualized and the reflection of a shared cultural context.

Habitus also reflects both agency and structural determinacy: the body's ways are forever a constitutive response to already existing social conditions, but they are also generative. The habitus engenders countless practices, which, as they reverberate in specific fields of action, reconstitute those fields in novel ways because there are al- ways gaps of indeterminancy-unintended consequences flow from unacknowledged conditions. For Bourdieu, habitus does not simply read off and reproduce practices from social structure, but neither does it succumb to a "fetishization of the indeterminacy of social structures" (McNay, 1999, p. 105). The habitus/field combination amounts to "an open system of dispositions that is constantly subjected to experiences, and therefore constantly affected by them in a way that either reinforces or modifies its structures" (Bourdieu \& Wacquant, 1992, p. 133).

Kasper's ecological habitus is defined as the

... ecologically relevant aspects of habitus. Everybody, whether aware of it or not, lives in, depends on, affects, and is affected by their ecosystem and the wider biosphere. Certain characteristics of habitus will be more relevant to those contexts, in whatever ways, than others. (Kasper, 2009, p. 9; see also Haluza-DeLay, 2007; Smith, 2001)

Kasper introduces a continuum between "ecologically supportive" and "ecologically antagonistic" lifestyle patterns. Important for her is the potential of the model to focus on relational process, between social, group, and personal elements of a life that contribute toward a position somewhere on that continuum. Kasper's empirical hopes for the model lie in its ability to identify nexuses of relationships and practices that foster a more or less ecologically supportive habitus, practices reciprocally embedded and embodied in the "field" of localized social and cultural configurations (e.g., distance from work, means of travel, shopping centers, leisure) and the broader context (e.g., advertising, consumerism).

One way of researching ecological habitus in practice is the study of environmental "success stories," as they may offer clues as to the relation set of practices that foster "strong" sustainable lifestyles: those that can offer a meaningful challenge to obdurate social norms and practices considered central to ecological degradation, from overconsumption to privatism. Intentional communities such as "ecovillages" provide an example of such a phenomenon, one that Kasper has studied empirically (2008). Here the level of analysis is not the individual but the set of practices that stitch together everyday practices in a meaningful cultural, personal (including embodiment and affect), and natural context. Perhaps there is the potential here to address more explicitly the importance of cultural validation for behavioral solutions to environmental problems.

Working ecovillages are argued by Kasper to provide a context in which the relationship between psychological, ecological, social, and spiritual dimensions of existence are sustained through everyday practices. These practices are manifest in regular meetings and the 


\section{ADAMS}

setting of rules which provide strong social reinforcement; the availability of information, from the technological to the philosophical, and the freeing up of time to make accessing that information possible; the close proximity of a relatively small number of people; the preservation of green space and maximization of pedestrian space within the ecovillage. According to one ecovillage resident, this organization reflects the realization on the part of burnt-out environmental activists that "information is not the place to start...the problems stem from a deeper source-how they [people] experience themselves in the world' (cited in Kasper, 2008, p. 20). Such a description speaks to the emphasis Kasper, and Bourdieu before her, place on the "deeper" and literal embodiment of problematic social practices.

In this framework, the environmental movement becomes important in the extent to which it can provide a "field" for developing alternative habitus via experiential/learning processes. It is in this sense that "ecovillages reflect [the] capacity to bring about change via the interaction of particular ways of thinking, perceiving, and doing on a daily basis...they seem to encourage the development of a particular type of ecological habitus" (Kasper, 2009). Ecological habitus therefore has relevance to ecopsychology as a way of both conceptualizing the intertwining of the psychological and the social and, potentially, predicting which psychosocial configurations are likely to engender "strong" sustainability.

\section{Articulating the Space of Interrelated Practices}

David Kidner's account of the enmeshing of psyche, nature, and culture is another vital contribution here (2001), particularly as he pays much more attention to the vital role of far-reaching social and cultural frames for the maintenance of environmentally destructive behavior and the development of viable alternatives. He argues that meaningful sites of transpersonal relationality are "ideologically occluded" in industrialized society, and he consistently asserts that it is this "space" that needs to be reclaimed. The industrialized individual is not lacking in terms of an "inner emptiness," then, but rather an affective relational extension. What is at stake for Kidner is no less than the development of cultural forms that can articulate and validate what is referred to with various borrowing from psychological theories as the "felt" or "somatic sense," "preconscious recognition," or the "unthought known" of human/nonhuman nature connectedness (Bollas, 1987). What we need, simply put, "is a way of talking and thinking about the world that effectively expresses our felt connection to the world...nurtured and supported by a sympathetic cultural frame" (Kidner, 2001, p. 255). For Kidner, existing articulations of a space of "reciprocal permeation" are understandably opaque and can feel insubstantial as they are as yet "materially unrealized" by a supportive cultural framework. Here we connect directly to sociological arguments and an underdeveloped theme of ecopsychology-the possibility of culturally validating practices of human-nature connectedness as a "solution" to environmental problems.

One way in which such practices have been approached concretely is the study of "trans-species dialogue." Kidner noted in 2001 that the "discontinuity between the 'animal' and 'human' realms is beginning to come under fire” (p. 94), and in the years since feminist scholars in particular have turned their attention to trans-species dialogue, defined as "material and emotional connections to nonhuman species" (Potts, 2010). The greatest potential here lies not in the empirical verification of the outcomes for human well-being of animal-assisted therapies but in a consideration of the relational processes between human and nonhuman others that constitutes what is felt as connectedness. A good example of this potential is Dulce M. Garcia's account of equine-facilitated learning in this journal (2010). She considers neglected dimensions of equine-facilitated learning which take us "towards a new ecology," and her points of emphasis echo closely the importance of the relational space between, rather than the separateness (or potential for ontological collapse) of, the "things" involved. She builds on research findings that indicate that equine-facilitated activities induce positive states of mind and increase ecological awareness. While the clinical psychological focus on change has been productive, Garcia is more interested in the "vast potential" of the communication dimension between horses and humans. She makes only tentative claims about the role horses play in constructing shared systems of meaning with and between humans; but she implies that the reciprocal permeation involved in "horse-human conversations," to borrow Kidner's phrase, is one way in which a human/nonhuman connectedness can be articulated.

Horse-human communication may be defined as non/preverbal, forcing humans to access a way of speaking and using language that is unfamiliar and archaic. Archaic is here taken, following Berman, to mean the "notion that in a literal or figurative sense, everything in the universe is alive and interrelated, and that we know the world through direct identification with it, or immersion in its phenomena (subject/object merger)" (Berman, 1981; Garcia, 2010, p. 87). Accounts, and of course experiences, of horse-human relationships thus provide us with one example of reciprocity between human/ nonhuman nature which could be meaningfully articulated culturally (for a similar discussion in relation to humans and bird life see Dickinson, 2010). These non/preverbal and archaic means of communication come closer to Kahn et al.'s ambition of developing a 
"nature language": "a way of speaking about patterns of interactions between humans and nature and their wide range of instantiations, and the meaningful, deep, and often joyful feelings that they engender" (2010, p. 59).

Garcia's focus potentially fleshes out precisely the relational element of one of the possible interaction patterns noted, but not developed, by Kahn et al.-“recognition by a nonhuman other"-not only in terms of the clinically measurable change it may engender in those humans involved but in terms of a socially and culturally meaningful articulation of a relationship, pointing toward alternative forms of communication. Preverbal dialogue between horses and humans is of course just one aspect of the relational space between human and nonhuman nature. While a fascinating example of a step toward an "ecopsychology that will find within language an accurate articulation of the human-nature relationship" (Greenway, 2009, p. 50), further developments are needed to understand how such conversations could on the one hand coalesce in ways which might prize us away from our existing ways of life and the obdurate material and symbolic infrastructures underpinning them and at the same time become meaningfully articulated and validated within alternative cultural frameworks.

\section{Conclusion}

There is limited scope in reaffirming the connection between nature and subjective or objective measures of well-being in experimental settings, particularly if that connection, or lack of it, is symptomatic of something else-everyday social practices. Ecopsychology could instead be at the forefront of conceptualizing individual human and nonhuman nature relatedness as embedded in lifestyle webs of sociocultural praxis, often taken for granted (Kasper, 2009). Those of a sociological bent will not be too surprised by the emphasis on social and cultural context and practices, though it is a timely reminder that such an emphasis does not require a slide into social constructionist nihilism or relativism when it comes to nature (Kidner, 2001). If we accept social practices as our basic unit of concern, we are addressing in a pragmatic way calls to occupy the space of processes and becoming, rather than the reproduction of obsolete dualism pitting individuals against nature, society, culture or each other. It may also continue Andy Fisher's attempts "to encourage the field to become more comprehensive and critical” (2002, p. xiii).

What makes us carry on with some social practices and not others; what makes us defect and be recruited to alternatives? This is a question that requires an understanding of affective investments that exceeds some of the developments outlined here (Lertzman, 2012; Widick, 2003). However, Elizabeth Shove rightly asserts that in the domain of environmentalism, the study of social practices as the interconnection of psyche and the social is an area "positively fizzing with potential" (2010, p. 283). It is also one in which ecopsychology is well positioned to draw from and contribute.

\section{REFERENCES}

Beck, U. (2010). Climate for change, or how to create a green modernity? Theory, Culture \&t Society, 27, 254-266.

Berman, M. (1981). The reenchantment of the world. Ithaca, NY: Cornell University Press.

Bollas, C. (1987). The shadow of the object: Psychoanalysis of the unthought known. New York, NY: Columbia University Press.

Bourdieu, P. (1977). Outline of a theory of practice (R. Nice, Trans.). Cambridge, UK: Cambridge University Press.

Bourdieu, P., \& Wacquant, L. (1992) An invitation to reflexive sociology. Cambridge, UK: Polity Press.

Cavalletto, G. (2007). Crossing the psycho-social divide: Freud, Weber, Adorno and Elias. Aldershot, UK: Ashgate.

Chatterton, P., \& Cutler, A. (2008). The rocky road to a real transition: The transition towns movement and what it means for social change. Available online at http://www.trapese.org

Davis, M. (2010). Who will build the Ark? New Left Review, 61, 29-46.

Garcia, D. M. (2010). Of equines and humans: Toward a new ecology. Ecopsychology, 2, 85-89.

Fisher, A. (2002). Radical ecopsychology: Psychology in the service of life. New York, NY: SUNY Press.

Fiske, S. T. (2012). Journey to the edges: Social structures and neural maps of intergroup processes. British Journal of Social Psychology, 51, 1-12.

Goffman, E. (1967). Interaction ritual: Essays on face-to-face behavior. Chicago, IL: Aldine Publishing.

Greenway, R. (2009). Robert Greenway: The Ecopsychology interview. Ecopsychology, 1, 47-52.

Haluza-DeLay, R. (2007). A theory of practice for social movements: Environmentalism and ecological habitus. Mobilization, 13, 205-218.

Hand, M., Shove, E., \&t Southerton, D. (2005). Explaining showering: A discussion of the material, conventional, and temporal dimensions of practice. Sociological Research Online, 10(2). Available online at http://www.socresonline.org.uk/10/ 2/hand.html

Holloway, J. (2010). Crack capitalism. London: Pluto Press.

Jackson, T. (2008). Sustainable consumption and lifestyle change. In A. Lewis (Ed.), Handbook of economic psychology (pp. 335-362). Cambridge, UK: Cambridge University Press.

Kahn, P. H., Jr., Ruckert, J. H., Severson, R. L., Reichert, A. L., \& Fowler, E. (2010). A nature language: An agenda to catalog, save, and recover patterns of humannature interaction. Ecopsychology, 2, 59-66.

Kasper, D. V. S. (2008). Redefining community in the ecovillage. Human Ecology Review, 15, 12-24.

Kasper, D. V. S. (2009). Ecological habitus: Toward a better understanding of socioecological relations. Organization \&t Environment, 22, 311-326.

Kidner, D. (2001). Nature and psyche: radical environmentalism and the politics of subjectivity. New York, NY: SUNY. 


\section{ADAMS}

Kingsnorth, P., \&t Hine, D. (2009). Uncivilisation: The Dark Mountain manifesto. Available online at http://dark-mountain.net/about/manifesto/. Last accessed August 23, 2012.

Kingsnorth, P., \& Hine, D. (2010). Editorial: It's the end of the world as we know it (and we feel fine). In Dark Mountain: Issue 1, 1-5.

Law, J., \& Urry, J. (2004). Enacting the Social. Economy and society, 33, 390-410.

Lertzman, R. (2012). Researching psychic dimensions of ecological degradation: Notes from the field. Psychoanalysis, Culture \& Society, 17, 92-101.

McNay, L. (1999). Gender, habitus and the field: Pierre Bourdieu and the limits of reflexivity. Theory, Culture \& Society, 16, 95-117.

Paidas, S. M. (2011). Psychologies of the environment: Searching for themes in the literature. Ecopsychology, 3, 125-138.

Potts, A. (2010). Introduction: Combating speciesism in psychology and feminism. Feminism \&t Psychology, 20, 291-301.

Räthzel, N., \& Uzzell, D. (2009). Transformative environmental education: A collective rehearsal for reality. Environmental Education Research, 15, 263-277.

Reser, J. P. (1995) Whither environmental psychology? The transpersonal ecopsychology crossroads. Journal of Environmental Psychology, 15, 235-257.

Roszak, T. (1992). The voice of the Earth: An exploration of ecopsychology. New York, NY: Simon \&t Schuster.

Schneider, J., \& Miller, G. (2011). The impact of "No Impact Man": Alternative hedonism as environmental appeal. Environmental Communication: A Journal of Nature and Culture, 5, 467-484.

Shove, E. (2003). Comfort, cleanliness and convenience: The social organization of normality. Oxford, UK: Berg.

Shove, E. (2010). Social theory and climate change: Questions often, sometimes and not yet asked. Theory, Culture \& Society, 27, 277-288.

Smith, M. (2001). An ethics of place: Radical ecology, postmodernity, and social theory. New York, NY: State University of New York Press.

Soper, K. (2007). Re-thinking the "good life": the citizenship dimension of consumer disaffection with consumerism. Journal of Consumer Culture, 7, 205-229.

Soper, K., Thomas, L., \& Ryle, M. (Eds.). (2009). The politics and pleasures of consuming differently. Basingstoke, UK: Palgrave.

Steg, J., \& Vlek, C. (2009). Encouraging pro-environmental behaviour: An integrative review and research agenda. Journal of Environmental Psychology, 29, 309-317.
Swim, J. K., Clayton, S. \& Howard, G. S. (2011). Human behavioral contributions to climate change: Psychological and contextual drivers. American Psychologist, $66,251-259$.

Szerszynski, B., \&t Urry, J. (2010). Changing climates: Introduction. Theory, Culture \&t Society, 27, 1-8.

Thompson, M. (2009). Reviewing ecopsychology research: Exploring five databases and considering the future. Ecopsychology, 1, 32-37.

Uzzell, D., \&t Räthzel, N. (2009). Transforming environmental psychology. Journal of Environmental Psychology, 29, 340-350.

Warde, A. (2004). Consumption and theories of practice. Journal of Consumer Culture, 5, 131-153

Warde, A. (2005). Consumption and theories of practice. Journal of Consumer Culture, 5, 131-153.

Webb, J. (2012). Climate change and society: The chimera of behaviour change technologies. Sociology, 46, 109-125.

Widick, R. (2003). Flesh and the free market: On taking Bourdieu to the options exchange. Theory and Society, 32, 679-723.

Address correspondence to:

Dr. Matt Adams

University of Brighton

SASS

Mayfield House

Falmer

Brighton BN1 9PH

United Kingdom

E-mail:matthew.adams@bton.ac.uk

Received: May 25, 2012

Accepted: July 17, 2012 